\title{
VYRESNIŲ PACIENTŲ, PIRMĄ KARTĄ BESIKREIPIANČIŲ I ATMINTIES SUTRIKIMŲ KABINETĄ, KOGNITYVINIŲ FUNKCIJŲ SUTRIKIMŲ YPATUMAI
}

\author{
Gabrielė Legotaitė ${ }^{1}$, Jurgita Knašienè $\dot{e}^{2,3}$, Gytė Damulevičiene் ${ }^{2}$ \\ ${ }^{1}$ Lietuvos sveikatos mokslu universiteto Medicinos akademijos Vidaus ligu klinika, \\ ${ }^{2}$ Lietuvos sveikatos mokslu universiteto Medicinos akademijos Geriatrijos klinika, \\ ${ }^{3}$ Kauno kolegijos Medicinos fakulteto Slaugos katedra
}

Raktažodžiai: kognityviniu funkciju sutrikimai, atminties sutrikimai, lengvas kognityvinis sutrikimas, demencija.

\begin{abstract}
Santrauka
Ivvadas. Pastaraisiais dešimtmečiais Lietuvoje nustatoma vis daugiau demencijos atvejų. Senstanti populiacija ir kraujagysliniai rizikos veiksniai gali būti susiję su šia tendencija, tačiau tikslus Alzheimerio ligos (AL) ir kraujagyslinès demencijos (KD) paplitimas tarp vyresnių pacientų nèra žinomas.

Tyrimo tikslas. Ivvertinti vyresnių pacientų, pirmą kartą besikreipiančių i Atminties sutrikimų kabinetą, kognityvinių funkcijų sutrikimų (KFS) ypatumus bei nustatyti sąsajas tarp KFS ir rizikos veiksnių, gretutinių ligų.

Tyrimo metodika. Atliktas populiacinis retrospektyvinis kohortinis tyrimas, naudojant ambulatoriniu kortelių duomenis. I tyrimą įtraukti $60 \mathrm{~m}$. ir vyresnio amžiaus 202 pacientai, kurie 2015 metais pirmą kartą kreipèsi ị Atminties sutrikimų kabinetą, esantị Všt Kauno klinikinès ligoninès I konsultacinejje poliklinikoje. Duomenų analizei naudota Microsoft Excel 2010 ir SPSS 22.0 programos. Pasirinktas stas tistinio reikšmingumo lygmuo $\alpha=0,05$. Kintamuju skirtumai lyginant kelias tiriamuju grupes ar ryšys tarp kintamujų laikomi statistiškai reikšmingais, kai $\mathrm{p}<\alpha(\mathrm{p}<0,05)$. Duomenų analizejje naudoti chi-kvadratu, Student'o t kriterijai, dispersinè analizè Anova, Spearmen'o ir Kendall tau-b koreliacijos koeficientai, aprašomoji statistika.

Tyrimo rezultatai. Išanalizuoti 202 pacientų $(\geq 60$ m. amžiaus) ambulatorinių kortelių duomenys. 82,7 proc. pacientų ( $\mathrm{n}=167)$ buvo nustatyti KFS: 81,4 proc. $(n=136)$ demencija, 18,6 proc. $(n=31)$ lengvas
\end{abstract}

kognityvinis sutrikimas (LKS). Demenciju pasisł kirstymas pagal sunkumo formą: sunki 15,4 proc., vidutinio sunkumo 72,1 proc., lengva 12,5 proc. Dažniausiai nustatyta KD - 41,9 proc. (subkortikinè 64,9 proc. atvejų), antra pagal dažnị - mišri demencija, kuri diagnozuota 34,6 proc. atvejų, trečia - demencija sergant Alzheimerio liga, 15,4 proc. LKS sutrikimas buvo susijęs su menkesniu išsilavinimu $(p<0,001)$, išemine širdies liga (IŠL) $(\mathrm{p}=0,030)$, hipertenzija $(\mathrm{p}=0,001)$. Demencija buvo susijusi su vyresniu amžiumi $(\mathrm{p}=0,001)$ ir menkesniu išsilavinimu $(p<0,001)$. KD buvo susijusi su smegenų infarktais $(p<0,001)$, IŠL $(p=0,001)$, hipertenzija $(\mathrm{p}=0,01)$, lètine išemine lakūnarine būkle $(p<0,001)$, šlapimo nelaikymu $(p=<0,001)$ ir griuvimais $(p=0,001)$. Mišri demencija buvo susijusi su IŠL $(p=0,026)$, hipertenzija $(p=0,007)$, šlapimo nelaikymu $(\mathrm{p}<0,001)$.

Išvados. Tarp pirmą kartą besikreipiančių pacientų i Atminties sutrikimų kabinetą KFS paplitimas siekè 82,7 proc. o dažniausiai nustatyta KD. Aukštas $\mathrm{KD}$ ir mišrios demencijos paplitimas buvo susijęs su kraujagysliniais rizikos veiksniais: smegenų infarktais, IŠL, hipertenzija, lètine išemine lakūnine būkle. Ankstyvos bendruomeninès intervencijos, kontroliuojant kraujagyslinius rizikos veiksnius, atliekant atrankines kognityviniu sutrikimu patikras bei nukreipiant pacientus ị specializuotus Atminties sutrikimų kabinetus turètų tapti prioritetu KFS prevencijai pagyvenusių žmonių populiacijoje.

\section{Ivadas}

Senėjanti populiacija, ilgėjanti gyvenimo trukmė lemia, jog daugèja žmonių, kuriems nustatomi kognityvinių (pažinimo) funkcijų sutrikimai (KFS). Sunkiausia KFS išraiška 
- demencija, kurios dažniausios priežastys yra Alzheimerio liga (AL) bei smegenų kraujagyslių patologija [1, 2].

Lengvas kognityvinis sutrikimas priklauso būklei tarp normalaus senejjimo ir demencijos. Jo paplitimas ambulatorinèje grandyje gali siekti apie $15,4-31,4$ proc. [3, 4]. Vilniaus universiteto ligoninès Santariškių klinikose buvo atliktas tyrimas, kuriame išanalizuoti 2003 - 2009 metais diagnozuoti LKS atvejai, didžioji jų dalis buvo nustatyta $65-85 \mathrm{~m}$ amžiaus pacientams [5]. Vertinant kelių metu duomenis, stebeta tendencija, kad kasmet nustatoma vis daugiau LKS atvejų, o pacientų amžius jaunèja. LKS konversija i demenciją nustatoma 14,46 proc. $-47,37$ proc. stebimų pacientų $[6,7]$. Mokslinių tyrimų duomenimis, nustatyti LKS rizikos faktoriai - moteriška lytis, vyresnis amžius, žemesnis išsilavinimas, hipertenzija, miokardo infarktas (MI), smegenų infarktas, širdies nepakankamumas, cukrinis diabetas (CD), dislipidemija, rūkymas, alkoholio vartojimas, depresija ir kiti $[7,8]$.

Ivairių tyrimų duomenimis, demencijos paplitimas skiriasi. $65 \mathrm{~m}$. ir vyresnio amžiaus populiacijoje jis gali siekti apie $6,4-8,2$ proc. [2,11]. Nustatyta, kad dažniausia demencijos priežastis yra Alzheimerio liga, rečiau būna kraujagyslinè, mišri demencijos [2, 11, 12]. Jaunesniems nei $65 \mathrm{~m}$. amžiaus amenims rečiau būna demencija sergant Alzheimerio liga nei $65 \mathrm{~m}$. ir vyresniems, atitinkamai 34 proc. ir 54 proc. [2]. Demencijos atsiradimas yra susijęs su vyresniu amžiumi, hipertenzija, depresija, šeimine demencijos anamneze, žemu išsilavinimu, galvos smegenu trauma [11]. Kraujagyslinems demencijoms priskiriamos demencijos, sąlygotos galvos smegenų kraujagysliu ligų. Bendroje populiacijoje ji gali sudaryti apie 1,6 proc., o tarp visų demencijų - 16 - 20 proc. $[2,13]$. İvairios patologinès būklès, susijusios su kraujagyslių pažeidimu, gali turèti įtakos KD išsivystyti. Rizikos veiksniams priskiriama hipertenzija, cukrinis diabetas, dislipidemija, išeminè širdies liga [14]. Diagnozuojant kraujagyslinę demenciją labai svarbus anamnezeje buvęs galvos smegenų insultas, jo ryšys su $\mathrm{KD}$ atsiradimu [15]. Neretai nustatoma mišri demencija, ypač pagyvenusio amžiaus žmonèms. Jai būdingi dvieju dažniausiai nustatomų demenciju - Alzheimerio ligos ir kraujagyslinės demencijos - požymiai. Diagnostika sudetinga, o paplitimas vertinant klinikopatologinius tyrimus yra labai ịvairus ir gali būti $2-60$ proc. Mažai žinoma ir apie specifinius rizikos veiksnius, dažniausiai nustatomi $\mathrm{AL}$ ir KD rizikos veiksniai [16].

Demencija - aktuali visuomenès sveikatos problema, kurią sprendžiant labai svarbi ankstyva diagnostika. Vis délto dažnai uždelsiama nustatant šią patologiją [9]. Amerikos gydytojų atliktoje literatūros apžvalgoje nurodytos priežastys, tikriausiai susijusios su nepakankamai gera de- mencijos diagnostika pirminès sveikatos priežiūros (PSP) istaigose. Vienas iš veiksnių - tai gydytojo patirties, žinių trūkumas, paciento skundų dèl KFS sumenkinimas, sutrikimų priskyrimas normaliam senejjimui, pacientas gyvena kaimo vietoveje, demencijos diagnozès baimè ir kiti veiksniai [10]. Demencijos tipo nustatymas yra svarbus dèl gydymo taktikos, ligos eigos bei prognozès. Laikotarpis, per kuri išryškèja simptomai, taip pat svarbus - Alzheimerio liga siejama su ne tokia aiškia pradžia, kaip KD. Demencijos diagnostikoje bei nustatant tipą svarbus vaidmuo tenka PSP įstaigoms [17]. 2004 metais atliktame tyrime buvo analizuojami 196 PSP gydytojų siuntimai dèl demencijos patikslinimo ị Neurologijos polikliniką. Analizès metu nustatyti siuntimo ir galutinès diagnozių nesutapimai: patvirtinta tik 40,74 proc. preliminarių diagnozių. Iš nustatytų 131 AL sergančių pacientų 70 atsiųsta su šia diagnoze, iš 42 nustatytų kraujagyslinių demencijų - 6, o mažiausiai siunčiant įtarta mišrių demencijų, iš 11 patvirtintų įtarta tik viena. Iš šiu duomenų matoma, jog iš 196 pacientų, kurie buvo atsiųsti dèl demencijos įtarimo, 66,84 proc. nustatyta demencija sergant AL, 21,43 proc. kraujagysliné demencija ir 5,61 proc. mišri demencija [18].

Dažnai LKS ar netgi demencijos požymiai „nurašomi“" normalaus senèjimo išraiškai, pacientai nesikreipia ị gydytoją, nèra tiriami, netiksliai nustatoma diagnozė [8]. Šios tendencijos stebimos ir Lietuvoje. Taip pat nèra aiškus demencijų paplitimas pagal tipus. Itariant ir diagnozuojant KFS, svarbus paciento ir gydytojų bendradarbiavimas, demencijos rizikos veiksnių nustatymas, atrankinè kognityvinių funkcijų patikra ir ankstyvas nukreipimas ị specializuotus Atminties sutrikimų kabinetus.

Darbo tikslas: ịvertinti vyresnių pacientų, pirmą kartą besikreipiančių i Atminties sutrikimų kabinetą, kognityvinių funkcijų sutrikimų ypatumus bei nustatyti sąsajas tarp KFS ir rizikos faktorių, gretutinių ligų.

\section{Tyrimo medžiaga ir metodai}

I tyrimą įtraukti 202 pacientai, kurie 2015 metais pirmą kartą kreipèsi ị Atminties sutrikimų kabinetą, esantị Všt Kauno klinikinès ligoninès I konsultacinèje poliklinikoje. Atrankos kriterijai: $60 \mathrm{~m}$. ir vyresni pacientai, kurie kreipèsi į Atminties sutrikimų kabinetą dèl atminties sutrikimu pirmą kartą. Buvo renkami ir analizuojami duomenys iš ambulatorinių kortelių: amžius, lytis, išsilavinimas, gyvenamoji vieta, nusiskundimų trukmè, gretutinès ligos, MMSE testo balai, laboratorinių tyrimų duomenys, kaklo kraujagyslių UG ir galvos KT tyrimo duomenys.

Rezultatai skaičiuoti naudojant Microsoft Excel 2010 ir SPSS 22.0 programas. Pasirinktas statistinio reikšmingumo lygmuo $\alpha=0,05$. Kintamujų skirtumai lyginant kelias ti- 
riamujų grupes ar ryšys tarp kintamujjų laikomi statistiškai reikšmingais, kai $\mathrm{p}<\alpha(\mathrm{p}<0,05)$. Duomenu analizejje naudoti chi-kvadratu, Student'o t kriterijai, dispersinè analizė Anova, Spearmen'o ir Kendall tau-b koreliacijos koeficientai, aprašomoji statistika.

\section{Rezultatai ir jų aptarimas}

Išanalizuoti 202 pacientų ( $\geq 60 \mathrm{~m}$. amžiaus) ambulatorinių kortelių duomenys. Moterys sudare 74,8 proc. $(\mathrm{N}=151)$, o vyrai $-24,2$ proc. $(\mathrm{N}=51)$ visų tiriamujų. Vi-

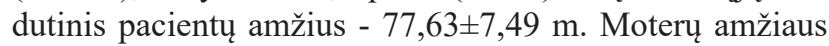
vidurkis $77,97 \pm 7,40$, vyru $-76,63 \pm 7,81 \mathrm{~m}$. Tiriamuosius suskirsčius pagal amžiaus grupes, gauta, kad daugiausia kreipèsi 75 - 79 m. amžiaus pacientų (1 lentelè).

Kognityvinių funkcijų sutrikimų paplitimas ir charakteristikos. Iš 202 konsultuotų ir ištirtų pacientų 82,7 proc. $(\mathrm{N}=167)$ nustatyti kognityvinių funkcijų sutrikimai: 81,4 proc. $(\mathrm{N}=136)$ - demencija (amžiaus vidurkis $79,41 \pm 7,08 \mathrm{~m}$.), 18,6 proc. ( $\mathrm{N}=31)$ - lengvas kognityvinis sutrikimas $(73,58 \pm 6,95 \mathrm{~m}$.). Kitiems 17,3 proc. $(\mathrm{N}=35)-$ KFS nenustatyta (amžiaus vidurkis $74,31 \pm 7,27$ m.). Atsižvelgiant ị MMSE testo ịvertinimus balais, demencijos skirstytos pagal sunkumo formą: sunki $(0-10$ balų), vidutinio sunkumo ( $11-20$ balų), lengva ( $21-24$ balai). Dažniausiai nustatyta vidutinio sunkumo forma $-72,1$ proc. visų demencijų (2 lentelè).

Vertintos demencijų charakteristikos. Didžiausią dalį, 41,9 proc., sudare pacientai, kuriems nustatyta kraujagyslinè demencija $(\mathrm{KD})(\mathrm{N}=57)$. Antra pagal dažni - mišri demencija, kuri diagnozuota 34,6 proc. $(\mathrm{N}=47)$ atvejų, trečia - demencija sergant Alzheimerio liga, 15,4 proc. $(\mathrm{N}=21)$. 4,4 proc. $(\mathrm{N}=6)$ sudare demencija, sergant kitomis ligomis, 2,2 proc. $(\mathrm{N}=3)$ - Parkinsono liga ir 1,5 proc. $(\mathrm{N}=2)$ - Piko liga.

Trys dažniausi nustatyti demencijų tipai - tai krauja-

1 lentelè. Pacientų pasiskirstymas pagal amžiaus grupes

\begin{tabular}{|l|c|c|c|c|c|c|}
\hline $\begin{array}{l}\text { Amžiaus inter- } \\
\text { valai }\end{array}$ & $\mathbf{6 0}-\mathbf{6 4} \mathbf{~ m .}$ & $\mathbf{6 5}-\mathbf{6 9} \mathbf{~ m .}$ & $\mathbf{7 0}-\mathbf{7 4} \mathbf{~ m .}$ & $\mathbf{7 5}-\mathbf{7 9} \mathbf{~ m .}$ & $\mathbf{8 0} \mathbf{- 8 4} \mathbf{~ m .}$ & $\geq \mathbf{8 0} \mathbf{~ m .}$ \\
\hline $\mathrm{N}$ (proc.) & $\begin{array}{c}11 \\
(5,4 \text { proc. })\end{array}$ & $\begin{array}{c}20 \\
(9,9 \text { proc. })\end{array}$ & $\begin{array}{c}33 \\
(16,3 \text { proc. })\end{array}$ & $\begin{array}{c}51 \\
(25,2 \text { proc. })\end{array}$ & $\begin{array}{c}48 \\
(23,8 \text { proc. })\end{array}$ & $\begin{array}{c}39 \\
(19,3 \text { proc. })\end{array}$ \\
\hline
\end{tabular}

2 lentelè. Pacientų pasiskirstymas pagal KFS ir amžiaus vidurkis

\begin{tabular}{|l|l|c|c|}
\hline KFS & \multicolumn{1}{|c|}{$\begin{array}{c}\text { Sunkumo } \\
\text { forma }\end{array}$} & N (proc.) & $\begin{array}{c}\text { Amžius (vidurkis } \pm \text { st. } \\
\text { nuokr.) (m.) }\end{array}$ \\
\hline \multirow{2}{*}{$\begin{array}{l}\text { Demen- } \\
\text { cija }\end{array}$} & Sunki & $21(15,4$ proc.) & $80,89 \pm 7,49$ \\
\cline { 2 - 4 } & $\begin{array}{l}\text { Vidutinio sun- } \\
\text { kumo }\end{array}$ & $98(72,1$ proc. $)$ & $79,39 \pm 7,51$ \\
\cline { 2 - 4 } & Lengva & $17(12,5$ proc. $)$ & $78,70 \pm 7,53$ \\
\hline
\end{tabular}

gyslinė demencija, mišri demencija ir demencija sergant Alzheimerio liga. Iš visų tiriamųjų, kuriems diagnozuota demencija sergant AL, 95,2 proc. buvo vélai prasidejusi $\mathrm{AL}(\mathrm{N}=20)$ (prasidejusi po $65 \mathrm{~m}$. amžiaus) ir tik vienam pacientui, 4,8 proc. - anksti prasidejusi AL (prasidejusi iki $65 \mathrm{~m}$. amžiaus). Kraujagyslinès demencijos tipai ir paplitimas buvo šie: subkortikinè KD - 64,9 proc. $(\mathrm{N}=37)$, kita KD 21,1 proc. $(\mathrm{N}=12)$, mišri kortikinè ir subkortikinė $\mathrm{KD}$ 14,0 proc. $(\mathrm{N}=8)$. Pasiskirstymas pagal priežastis, lyginant su kitų šalių duomenimis, skiriasi. Daugelyje atliktų tyrimų nustatyta, kad dažniausia demencijos priežastis yra Alzheimerio liga, rečiau būna kraujagyslinè, mišri demencijos $[2,11,12]$. Kraujagyslinems demencijoms priskiriamos demencijos, sąlygotos galvos smegenų kraujagyslių ligų. Bendroje populiacijoje ji gali sudaryti apie 1,6 proc., o tarp visų demencijų - 16 - 20 proc. [2,13]. İvairios patologinès būklès, susijusios su kraujagyslių pažeidimu, turèti įtakos KD išsivystyti.

Kognityvinių funkcijų sutrikimai ir demografiniai rodikliai. Dispersinès analizès rezultatai atskleide, kad yra statistiškai reikšmingas ryšys tarp diagnozès ir pacientų amžiaus $(p<0,001)$. Pacientai, kuriems diagnozuota demencija, yra statistiškai reikšmingai vyresni, nei tie, kuriems KFS nenustatyta $(\mathrm{p}=0,001)$ arba nustatytas LKS $(p<0,001)$. Pacientų be KFS ir su LKS amžius statistiškai reikšmingai nesiskyrè $(\mathrm{p}=0,908)$.

Pagal nusiskundimų trukmę metais pacientai suskirstyti i keturias grupes: 1 - nusiskundimai trunka mažiau nei 1 metus, 2 - nuo 1 iki $2 \mathrm{~m} ., 3$ - nuo 2 iki $3 \mathrm{~m}$., 4 -3 ir daugiau metų. 30 pacientų (19 moteru, 11 vyrų) duomenys nebuvo žinomi, todèl jie ị analizę neįtraukti. Iš surinktų duomenų matoma, jog pacientai dažniausiai kreipèsi į Atminties sutrikimų kabinetą praejus 3 arba daugiau metų nuo nusiskundimų pradžios (3 lentelè).

Rastas teigiamas silpnas ryšys - kuo anamnezeje ilgesni laikotarpi trunka pacientų nusiskundimai, tuo dažniau nustatyta demencija $(\mathrm{p}=0,002)$. Tai parodo uždelstą ligos diagnozavimą. Vèlyva KFS diagnostika bei gydymas yra aktuali problema daugelyje pasaulio šalių $[9,10]$.

Nenustatyta statistiškai reikšmingo ryšio tarp pacientų lyties ir nusiskundimų trukmès $(\mathrm{p}=0,623)$ - pirmą kartą i Atminties sutrikimų kabinetą vyrai ir moterys kreipèsi praèjus panašiam laikotarpiui nuo skundų pradžios.

Taip pat vertintas ryšys tarp pacientų nusiskundimų trukmès ir gyvenamosios vietos (miestas, miestelis, kaimas). Statistiškai reikšmingo ryšio nenustatyta $(\mathrm{p}=0,750)$. Negalime teigti, kad konkretaus tipo gyvenvietėje gyvenančių 
3 lentelè. Pacientų pasiskirstymas pagal nusiskundimų trukmę

\begin{tabular}{|l|l|l|l|l|}
\hline Lytis & Iki $\mathbf{1}$ m. & $\mathbf{( 1 - 2 )} \mathbf{~ m . ~}$ & $\mathbf{( 2 - 3 )} \mathbf{~ m . ~}$ & $\mathbf{3}$ ir daugiau $\mathbf{~ m .}$ \\
\hline Moterys & $4(3,0$ proc. $)$ & $22(16,7$ proc. $)$ & $32(24,2$ proc. $)$ & $74(56,1$ proc. $)$ \\
\hline Vyrai & $2(5,0$ proc. $)$ & $7(17,5$ proc. $)$ & $6(15,0$ proc. $)$ & $25(62,5$ proc. $)$ \\
\hline Visi & $6(3,5$ proc. $)$ & $29(16,9$ proc. $)$ & $38(22,1$ proc. $)$ & $99(57,5$ proc. $)$ \\
\hline
\end{tabular}

pacientų nusiskundimai truktų ilgesnị laiką ir jie delstų kreiptis pagalbos ị specialistus. Kitų autorių atliktuose darbuose nustatyta, jog toliau nuo gydymo ịstaigų, kaimuose gyvenantys bei reikalingo transporto neturintys žmonès ilgiau nesikreipia ị gydytojus [10].

Ieškota sąsajų tarp pacientų išsilavinimo ir kognityvinių funkcijų sutrikimų. Nustatytas statistiškai reikšmingas silpnas neigiamas ryšys tarp KFS ir išsilavinimo - demencija sergantiems pacientams būdingas žemesnis išsilavinimas $(\mathrm{p}<0,001)$.

Kognityvinių funkcijų sutrikimai ir gretutinès būklès. Tiriant, ar pacientams su KFS būdingos tam tikros gretutinès patologijos, detaliau analizuoti 191 paciento sveikatos būklès duomenys (pacientų, kuriems nustatytas LKS, mišri demencija, demencija sergant Alzheimerio liga, kraujagyslinė demencija, taip pat kuriems KFS nenustatyti).

Nustatytas statistiškai reikšmingas ryšys tarp tiriamųjų grupių ir anamnezeje buvusio galvos smegenų insulto $(p<0,001)$. Sergantiems kraujagysline demencija statistiškai reikšmingai dažniau buvęs galvos smegenų insultas nei likusioms pacientu grupèms: pacientams be KFS $(p=0,013)$, sergantiems LKS $(p=0,029), \operatorname{AL}(p=0,001)$, mišria demencija $(\mathrm{p}=0,001)$.

Analizuojant kardiovaskulinių ligų ir kognityvinių funkcijų veiklos sutrikimų sąsajas, statistiškai prasmingas ryšys buvo su išemine širdies liga (IŠL) $(p=0,003)$ ir hipertenzine liga $(\mathrm{p}=0,009)$. Pacientai su LKS statistiškai reikšmingai dažniau serga IŠL nei pacientai be KFS $(\mathrm{p}=0,030)$. KD sergantiems pacientams ši liga diagnozuota statistiškai reikšmingai dažniau nei pacientams be KFS $(\mathrm{p}=0,001)$ ir sergantiems demencija dèl AL $(\mathrm{p}=0,004)$. Mišria demencija sergantiems IŠL dažnesnè nei pacientams be KFS $(p=0,026)$. Su visomis tiriamuju grupèmis susijug si HL, išskyrus demenciją sergant AL: pacientai be KFS $(\mathrm{p}=0,007)$, su LKS $(\mathrm{p}=0,001)$, mišria demencija $(\mathrm{p}=0,007)$, $\mathrm{KD}(\mathrm{p}=0,01)$. Nenustatyta statistiškai reikšmingo ryšio tarp tiriamų grupių ir miokardo infarkto $(\mathrm{p}=0,769)$, širdies nepakankamumo $(\mathrm{p}=0,410)$.

Rezultatų analizè rodo, kad nebuvo statistiškai reikšmingų sąsajų tarp kognityvinių funkcijų veiklos sutrikimų ir endokrininių ligų: cukrinio diabeto $(\mathrm{p}=0,754)$, netoksinès mazginès strumos $(\mathrm{p}=0,505)$, hipotirozès $(\mathrm{p}=0,858)$.

Statistiškai reikšmingas ryšys yra tarp KFS ir šlapimo nelaikymo $(\mathrm{p}<0,001)$. Poriniai palyginimai tarp skirtingų diagnozių tiriamujų grupių atskleide, kad sergantys KD statistiškai reikšmingai dažniau nelaiko šlapimo nei pacientai be KFS $(p<0,001)$ ar turintys lengvą kognityvini sutrikimą $(\mathrm{p}=0,001)$. Asmenys, sergantys mišria demencija, statistiškai reikšmingai dažniau nelaiko šlapimo nei tiriamieji be KFS $(p<0,001)$ ar turintys LKS $p=0,014)$. Sergantys AL dažniau nelaiko šlapimo nei pacientai be KFS $(p<0,007)$. Nèra statistiškai reikšmingo ryšio tarp pacientams nustatyto KFS ir inkstų funkcijos nepakankamumo $(\mathrm{p}=0,792)$.

Nustatytas statistiškai reikšmingas ryšys tarp KFS ir griuvimų $(p=0,001)$. Poriniai palyginimai tarp skirtingų diagnozių grupių atskleidé, kad pacientams, kuriems diagnozuota KD, statistiškai reikšmingai dažniau būdingi griuvimai nei asmenims be KFS ( $p=0,001)$, su LKS $(p=0,002)$ ar demencija sergant $\mathrm{AL}(\mathrm{p}=0,008)$. Griuvimai yra siejami su kraujagyslinès demencijos diagnoze. Anamnezèje buvusios galvos traumos neturejo sąsajų su KFS ( $p=0,328)$.

Ieškant sąsajų tarp įvairaus sunkumo KFS ir kitų psichiatrinių ligų, statistiškai reikšmingas ryšys su organine depresija $(p=0,083)$ nenustatytas. Taip pat nebuvo sąsajų su ivvairiomis onkologinemis ligomis $(\mathrm{p}=0,203)$, anemijomis $(\mathrm{p}=0,403)$, dislipidemijomis $(\mathrm{p}=0,092)$.

Atliktoje galvos smegenų KT nustatyti seni išeminiai lakūniniai pakitimai sietini su kognityvinių funkcijų sutrikimais $(\mathrm{p}<0,001)$. Sergantiems kraujagysline demencija statistiškai reikšmingai dažniau nustatyti seni išeminiai lakūniniai pakitimai galvos smegenų KT nei pacientams su mišria demencija $(p<0,001)$ ar demencija sergant $A L$ $(\mathrm{p}<0,001)$.

\section{Išvados}

1. Tarp pirmą kartą besikreipiančiu pacientų i Atminties sutrikimų kabinetą KFS paplitimas siekė 82,7 proc. o dažniausiai nustatyta KD.

2. Didelis KD ir mišrios demencijos paplitimas buvo susijęs su kraujagysliniais rizikos veiksniais: smegenų infarktais, IŠL, hipertenzija, lètine išemine lakūnine būkle.

3. Ankstyvos bendruomeninès intervencijos, kontroliuojant kraujagyslinius rizikos veiksnius, atliekant atrankines kognityvinių sutrikimu patikras bei nukreipiant pacientus i specializuotus Atminties sutrikimų kabinetus turètų tapti prioritetu KFS prevencijai pagyvenusių žmonių populiacijoje.

\section{Literatūra}

1. Damuleviciene G, Lesauskaite V, Knasiene J, Macijauskiene $\mathrm{J}$. Use of technologies in maintaining autonomy of frail older 
persons. Medicina (Kaunas). 2010; 46 (1):35-42.

2. Van der Flier WM, Scheltens P. Epidemiology and risk factors of dementia. J Neurol Neurosurg Psychiatry 2005 Dec; 76(5): v2-v7.

http://dx.doi.org/10.1136/jnnp.2005.082867

3. Luck T, Riedel-Heller SG, Kaduszkiewicz H, Bickel H, Jessen F, Pentzek M. et al. Mild cognitive impairment in general practice: age-specific prevalence and correlate results from the German study on ageing, cognition and dementia in primary care patients (AgeCoDe). Dement Geriatr Cogn Disord 2007; 24(4):307-16

http://dx.doi.org/10.1159/000108099

4. Juncos-Rabadán O, Pereiro AX, Facal D, Lojo C, Caama-o JA, Sueiro J. et al. Prevalence and correlates of mild cognitive impairment in adults aged over 50 years with subjective cognitive complaints in primary care centers. Geriatr Gerontol Int 2014 Jul;14(3):667-73.

http://dx.doi.org/10.1111/ggi.12157

5. Viesulaitė B., Kaubrys G., Audronytė E., Žalienė S. Lengvo kognityvinio sutrikimo diagnostika Vilniaus universiteto ligoninès Santariškių klinikose 2003-2009 metais. Neurologijos seminarai, 2010; 14(46): 250-256.

6. Staekenborg SS, Koedam EL, Henneman WJ, Stokman P, Barkhof F, Scheltens P, van der Flier WM. Progression of mild cognitive impairment to dementia: contribution of cerebrovascular disease compared with medial temporal lobe atrophy. Stroke 2009 Apr; 40(4):1269-74.

http://dx.doi.org/10.1161/STROKEAHA.108.531343

7. Keyimu K, Zhou XH, Miao HJ, Zou T. Mild cognitive impairment risk factor survey of the Xinjiang Uyghur and Han elderly. Int J Clin Exp Med 2015; 8(8):13891-13900.

8. Lopez OL, Jagust WJ, Dulberg C, Becker JT, DeKosky ST, Fitzpatrick A. Risk factors for mild cognitive impairment in the Cardiovascular Health Study Cognition Study: part 2. Arch Neurol. 2003 Oct;60(10):1394-9.

http://dx.doi.org/10.1001/archneur.60.10.1394

9. Luzny J, Holmerova I, Wija P, Ondrejka I. Dementia still diagnosed too late - Data from the Czech Republic. Iran J Public Health 2014 Oct; 43(10):1436-43.

10. Bradford A, Kunik ME, Schulz P, Williams SP, Singh H. Missed and delayed diagnosis of dementia in primary care: prevalence and contributing factors. Alzheimer Dis Assoc Disord 2009 Oct-Dec;23(4):306-14.

http://dx.doi.org/10.1097/WAD.0b013e3181a6bebc

11. Llibre Jde J, Fernández Y, Marcheco B, Contreras N, López AM, Otero M. Prevalence of dementia and Alzheimer's disease in a Havana municipality: a community-based study among elderly residents. Medicc Rev 2009 Apr; 11(2):29-35.

12. Rizzi L, Rosset I, Roriz-Cruz M. Global epidemiology of dementia: Alzheimer's and vascular types. Biomed Res Int 2014; 2014:908915.

http://dx.doi.org/10.1155/2014/908915
13. EL Cunningham, B McGuinness, B Herron, AP Passmore. Dementia. Ulster Med J 2015 May; 84(2): 79-87.

14. Chandra M, Anand KS. Vascular disease burden in Indian subjects with vascular dementia. Australas Med J 2015 Jul 31;8(7):227-34.

http://dx.doi.org/10.4066/AMJ.2015.2390

15. Pikūnienė I., Viršilas M., Gleiznienė R. Kraujagyslinė demencija. Medicinos teorija ir praktika, 2015; 21(41): 487-495. http://dx.doi.org/10.15591/mtp.2015.077

16. Zekry D, Gold G. Management of mixed dementia. Drugs Aging. 2010 Sep 1;27(9):715-28. http://dx.doi.org/10.2165/11538250-000000000-00000

17. Robinson L, Tang E, Taylor JP. Dementia: timely diagnosis and early intervention. BMJ. 2015 Jun 16;350:h3029. http://dx.doi.org/10.1136/bmj.h3029

18. Kriščiūnaitė D., Pauža V., Mikalauskienė L. Demencijos: diagnostika pirminejje sveikatos priežiūros grandyje. Kaunas, JMTK;2004;

19. Varela G, Varona L, Anderson K, Sansoni J. Alzheimer's care at home: a focus on caregivers strain. Prof Inferm 2011 AprJun;64(2):113-7.

\section{CHARACTERISTICS OF COGNITIVE DISORDERS OF THE OLDER PATIENTS VISITING THE MEMORY CLINIC FOR THE FIRST TIME}

G. Legotaitė, J. Knašienè, G. Damulevičienè

Key words: cognitive disorders, mild cognitive impairment, dementia.

Summary

Introduction. The prevalence of dementia in Lithuania has risen dramatically in past decades. The ageing population and vascular risk factors may contribute to this rise. The proportions of Alzheimer's disease (ADD) and vascular dementia (VAD) in older population is not clear.

Aim. Our aim was to evaluate the characteristics of cognitive disorders of the older patients, visiting the Memory clinic for the first time and to identify the relationships between cognitive disf orders and risk factors, comorbidities.

Methods. We used a population-based retrospective cohort study design and extracted data from Memory clinic database. The research involved 202 patients of 60 and over year-old, who visited the Memory clinic in I Consulting Clinic of Kaunas Clinical Hospital, in 2015 for the first time. The statistical analysis of the data was performed using the software SPSS 22.0. The selected statistical significance level was $\alpha=0,05$. The differences of variables, while comparing several groups of subjects, or relationships between variables were considered as statistically significant when $\mathrm{p}<\alpha$ $(\mathrm{p}<0,05)$. Chi-square, Student t-test, analysis of variance Anova, Spearmen and Kendall tau-b correlation coefficients, descriptive statistics were used in the data analysis.

Results: 202 patient's ( $\geq 60$ year-old) data were analyzed. $82,7 \%$ of patient's $(n=167)$ had cognitive disorders: $81,4 \%(n=136)$ dementia, $18,6 \%(n=31)$ mild cognitive impairment (MCI). De- 
mentia, according to severity: severe $15,4 \%$, moderate $72,1 \%$, mild $12,5 \%$. The most common was VAD - in $41,9 \%$ of cases (subcortical $64,9 \%$ ), mixed dementia - $34,6 \%$, ADD - $15,4 \%$, other $-4,4 \%$. MCI has relationship with lower education $(\mathrm{p}<0,001)$, ischaemic heart disease (IHD) $(p=0,030)$, hypertension $(p=0,001)$. Dementia is associated with older age $(p=0,001)$ and lower education of the patients $(\mathrm{p}<0,001)$. VAD is associated with strokes $(\mathrm{p}<0,001)$, IHD $(\mathrm{p}=0,001)$, hypertension $(\mathrm{p}=0,01)$, ischemic lacunar state $(p<0,001)$, urinary incontinence $(p=<0,001)$ and falls $(p=0,001)$. Mixed dementia has relationship with $\operatorname{IHD}(\mathrm{p}=0,026)$, hypertension $(\mathrm{p}=0,007)$, urinary incontinence $(\mathrm{p}<0,001)$.

Conclusions. The prevalence of cognitive disorders among the older patients visiting the Memory clinic for the first time is high $(82,7 \%)$ and the most common was VAD. The high prevalence of VAD and mixed dementia is associated with vascular risk factors - strokes, IHD, hypertension, chronic ischemic lacunar state. Community based early interventions controlling vascular risk factors, cognitive function screening and patients referral to Memory clinics have a priority in prevention of cognitive disorders in older population.

Correspondence to: jurgaknasiene@gmail.com

Gauta 2016-09-05 